\title{
0737. Statins protect the vasculature from excessive Angpt-2 production in sepsis
}

\author{
K Thamm ${ }^{1}$, C Ghosh², JT Kielstein ${ }^{1}$, WC Aird ${ }^{2}$, A Santel ${ }^{3}$, SM Parikh², S David ${ }^{1 *}$ \\ From ESICM LIVES 2014 \\ Barcelona, Spain. 27 September - 1 October 2014
}

\section{Introduction}

Sepsis is a syndrome of systemic inflammation arising from infection that constitutes a top-ten cause of adult mortality. The recent withdrawal of a specific sepsis therapeutic has diminished pharmaceutical enthusiasm for developing novel drugs in this domain. Angiopoietin-2 (Angpt-2) is an endothelial-derived protein that potentiates vascular inflammation and permeability and may be involved in sepsis pathogenesis.

\section{Objectives}

We set out to screen well-established drugs for their Angpt-2 lowering potential to ameliorate sepsis morbidity and to analyse the underlying molecular mechanism.

\section{Methods}

\section{In vitro}

FDA-approved library screening in human umbilical vein endothelial cells (HUVECs) and confirmation via Angpt-2 ELISA and quantitative RT-PCR.

\section{In vivo}

Murine experimental sepsis was induced both by endotoxin (LPS) and cecal ligation and puncture (CLP). Mice were either treated with an Angpt-2 specific siRNA, simvastatin, or both and survival as well as the direct effect on Angpt-2 production was assessed by RT-PCR. In men: We analyzed circulating Angpt-2 levels in a retrospective matched case-control study in individuals with septic shock.

\section{Results}

We found that simvastatin reduced endothelial Angpt-2 release and transcription in a time- and dose dependent manner in HUVECs. This effect required Simvastatin's

${ }^{1}$ Hannover Medical School, Hannover, Germany

Full list of author information is available at the end of the article
HMG-CoA reductase activity. Similarly, in vivo simvastatin reduced the transcription of Angpt-2 murine lungs. In septic mice, specific inhibition of Angpt-2 in the pulmonary endothelium via an RNAi approach improved survival by $50 \%(\mathrm{p}=0.002)$. Simvastatin equally improved survival, but the combination of Angpt-2 siRNA and simvastatin showed no additive benefit indicating that simvastatin might act via Angpt-2 inhibition. To investigate a potential link between statins and Angpt-2 in humans, we performed a matched case-control study in critically ill subjects and found that prior statin use was associated with lower circulating Angpt-2.

\section{Conclusions}

In an unbiased approach Simvastatin was found to inhibit Angpt-2 production in vitro. This observation could be confirmed in vivo in different murine models of the disease. Our data indicate that a potential beneficial effect of prior statin use in septic humans might be promoted via the Angpt-2/Tie2 axis. Therefore, "point of care" screening for circulating Angpt-2 in candidates for a clinical sepsis trial might help to identify those individuals that benefit from a statin treatment.

Grant acknowledgment

SD is supported by the DFG (DA 1209/4-1).

\section{Authors' details}

${ }^{1}$ Hannover Medical School, Hannover, Germany. ${ }^{2}$ Harvard Medical School, Center for Vascular Biology Research, Boston, USA. ${ }^{3}$ Silence Therapeutics AG, Berlin, Germany.

Published: 26 September 2014

doi:10.1186/2197-425X-2-S1-P59

Cite this article as: Thamm et al:: 0737. Statins protect the vasculature from excessive Angpt-2 production in sepsis. Intensive Care Medicine

Experimental 2014 2(Suppl 1):P59.

\section{SpringerOpen ${ }^{\circ}$}

(c) 2014 Thamm et al; licensee Springer. This is an Open Access article distributed under the terms of the Creative Commons Attribution License (http://creativecommons.org/licenses/by/2.0), which permits unrestricted use, distribution, and reproduction in any medium, provided the original work is properly cited. 